\title{
Selective Induction of Apoptosis by Azadarichta indica Leaf Extract by Targeting Oxidative Vulnerabilities in Human Cancer Cells
}

\author{
Alessia Roma ${ }^{1}$, Pamela Ovadje ${ }^{1}$, Matthew Steckle ${ }^{1}$, Leah Nicoletti ${ }^{1}$, Ammar Saleem ${ }^{2}$, John T. Arnason ${ }^{2}$ and Siyaram \\ Pandey $^{1}$ \\ ${ }^{1}$ University of Windsor, 401 Sunset Ave, Windsor, ON. ${ }^{2}$ Department of Biology, University of Ottawa, ON.
}

Received, July 7, 2015; Revised, August 30, 2015; Accepted, November 8, 2015; Published, November 8, 2015.

\begin{abstract}
Purpose: Natural products have been a great source of medications used in conventional medicines for the treatment of various diseases; more importantly, they have played a significant role in the development of anti-cancer drugs for a number of decades. The benefits to employing whole extracts of natural health products, rather than a single ingredient, for cancer treatment remains unexplored. Our research group has previously demonstrated the potential anti-cancer benefits of several natural health products (NHPs), prompting further studies into other NHPs, such as Neem (Azadarichta indica), a tree native to India and has been used in Ayurvedic medicine for over 4000 years. The objective of this study is to determine the possible anti-cancer potential of aqueous and ethanolic Neem leaf extracts (NLEs) and to identify the specific mode(s) of action. Methods: Cells were treated with NLE and cell viability was then assessed using a water-soluble tetrazolium salt. Cell death was confirmed using the fluorescent dye propidium iodide and apoptosis was identified using the Annexin- $\mathrm{V}$ binding assay. Mitochondrial membrane permeabilization was visualized using JC-1 staining and the production of whole cell and mitochondrial ROS was measured with 2',7'-dichlorodihydrofluorescein diacetate $\left(\mathrm{H}_{2}\right.$ DCFDA) and Amplex Red, respectively. In vivo efficacy of aqueous NLE was assessed in human tumour xenografts in CD-1 nu/nu immunocompromised mice. Results: Results indicate that both ethanolic and aqueous extracts of Neem leaf were effective in inducing apoptosis in leukemia and colon cancer cells, following destabilization of the mitochondrial membrane. Furthermore, an increase in the production of reactive oxygen species (ROS) was observed in cancer cells treated with NLEs, indicating that oxidative stress may play a role in the mechanism of cell death. Additionally, in vivo results showed that aqueous NLE (delivered orally) was well tolerated and inhibited tumour growth of human xenografts in mice. Conclusions: These findings suggest the potential of NLEs as safer and effective alternatives to conventional chemotherapy.
\end{abstract}

This article is open to POST-PUBLICATION REVIEW. Registered readers (see "For Readers") may comment by clicking on ABSTRACT on the issue's contents page.

\section{INTRODUCTION}

Cancer is a growing health problem affecting millions of people worldwide. In 2012, it was estimated that 32.6 million people were suffering from cancer, and it is predicted that $18.5 \%$ of the world's population will likely develop cancer before the age of seventy-five (1). Cancer is often defined as uncontrolled cell proliferation resulting from cells which evade certain regulatory mechanisms that maintain cell homeostasis resulting in the hallmarks of cancer (2). One of these hallmarks is resistance to programmed cell death processes, like apoptosis. There are two main apoptotic pathways that are currently known: [1] the extrinsic pathway that is activated by extracellular stimuli and [2] the intrinsic pathway, which involves internal signals converging on the mitochondria, leading to its permeabilization and the release of pro-apoptotic factors (3). Apoptosis, as well as other forms of programmed cell death, can be mediated by the production of reactive oxygen species (ROS). Often times, cytotoxic agents like chemotherapeutics, will either activate cell surface death receptors or will directly affect the

\footnotetext{
Corresponding Author: Siyaram Pandey, Department of Chemistry and Biochemistry, Essex Hall Room 277-1, University of Windsor, 401 Sunset Ave, Windsor, ON Canada, E-mail: spandey@uwindsor.ca
} 
mitochondria by disturbing its outer membrane integrity, causing an increase in ROS production. Considering that deregulated apoptosis plays an important role in the development of cancer, exploitation of the various apoptotic mechanisms can prove to be useful targets for the development of cancer therapies.

The most common cancer therapies, including radiation, and chemotherapy, are more often than not associated with very harsh side effects in patients mostly due to non-selective targeting of healthy cells (4). Considering these limitations and disadvantages, it is critical that new treatment options are developed to target the major hallmarks of cancer, while also minimizing the harsh side effects associated with current chemotherapies.

Natural products were the first and only treatments available to mankind before the age of modern medicine. Even today, a majority of the medicines in use are derived from natural products and their analogues (5). Daily intake of certain natural products have been shown to possess cancer preventive properties by inhibiting or delaying the effects of carcinogens and protecting against cellular deregulations (6). In addition to cancer prevention, natural products have also made an impact in cancer treatment with approximately $75 \%$ of current chemotherapies being derived from natural products (7). Neem (Azadirachta indica), is a tree of the Meliaceae family of plants that is native to India, where it is considered one of the most important plants worldwide. Specifically, its documentation in ancient literature considered "the foundation of the Indian system of natural treatment" has established its importance in disease treatment. Each part of the tree has been used to treat various illnesses like Malaria, oral infections and diabetes (8). Recently, researchers have focused their attention on the anticancer properties of NLEs in different cancer cells (9). These studies revealed that varying preparations of Neem leaf are able to induce apoptosis, inhibit cell proliferation, modulate transcription factors involved in oncogenesis and enhance anti-tumour immune responses in these cancers (10-12). Given these points, it is clear that Neem extracts have a high potential for the development as an anti-cancer therapy. Granted this, aqueous Neem leaf extract has not been studied as throughly and there are numerous descrepancies between various mechanistic studies, as well, a lack of a demonstration of selectivity against cancer cells warrants furthur investigation to address these questions.

In this study, we analyze the anti-cancer effects of both aqueous and ethanolic extracts of Neem leaf and attempt to identify any differences in the mechanism leading to tumour inhibition. Results indicate that both aqueous and ethanolic NLE are able to induce apoptosis in colon cancer and leukemia cells selectively without affecting normal cells treated under identical conditions. Furthurmore, the induction of apoptosis by NLE in cancer cells occurs via the destabilization of the mitochondrial membrane potential. It is hypothesized that oxidative stress may play a mechanistic role, as an increase in ROS was observed in cells treated with aqueous and ethanolic NLE. In addition, in vivo efficacy studies showed that oral administration of aqueous extracts inhibited tumour growth of human tumour xenografts in nude mice.These findings suggest that aqueous and ethanolic NLE as a natural health product could be a safer and effective cancer therapy alternative.

\section{MATERIALS AND METHODS}

\section{Cell Culture}

The human acute T-cell leukemia cell line E6-1 (Jurkat) (American Type Cell Collection (ATCC), Manassas, VA, USA. Cat. No. TIB 152) was cultured in RPMI1640 Medium (Sigma Aldrich, Mississauga, ON, CA. Cat. No. R8758), supplemented with $10 \%$ fetal bovine serum (FBS) (Thermo Scientific, Waltham, MA, USA. Cat. No.10091-148) and 0.4\% $(\mathrm{v} / \mathrm{v})$ gentamicin (Gibco, BRL, VWR, Mississauga, ON, CA. Cat. No.15750-060). The human colorectal adenocarcinoma HT-29 cell line (ATCC, Manassas, VA, USA Cat. No. CRL-1687) was cultured in McCoy's Medium 5a (Gibco BRL, VWR, Mississauga, ON, CA. Cat. No.16600-082) supplemented with $10 \%(\mathrm{v} / \mathrm{v})$ FBS and $0.4 \%(\mathrm{v} / \mathrm{v})$ gentamicin. Normal human fibroblasts (NHFs) were grown in Minimal Essential Medium with Earle's Balanced Salts (MEM/EBSS), (Thermo Scientific, Waltham, MA, USA. Cat. No.61100-152), supplemented with $15 \%$ FBS, $10 \%(\mathrm{v} / \mathrm{v})$ NonEssential Amino Acids (Gibco BRL, Mississauga, ON, CA. Cat. No.11140-050), and $0.4 \%$ (v/v) gentamicin. The normal-derived colon mucosa (NCM460) cell line (INCELL Corporation, LLC., San Antonio, TX, USA.) were grown in RPMI1640 
Medium supplemented with $10 \%$ FBS and $0.4 \%$ (v/v) gentamicin. Human nucleated blood cells were purified from peripheral blood, obtained from healthy volunteers, with the approval of the University of Windsor ethical committee, REB\# 30887. To collect the whole blood, BD Vacutainer Cell Preparation Tubes (CPT) (Becton Dickinson, Franklin Lakes, N.J., USA. Cat. No.362753) were used to separate the mononuclear cells by density gradient centrifugation. Specifically, the whole blood was spun down in a tabletop low-speed centrifuge at $2900 \mathrm{rpm}$ for 30 minutes at room temperature. Following centrifugation, the mononuclear cells, platelets and plasma are found in the top layer, while red blood cells are found in the polyester gel. The mononuclear cells were collected and cultured in AIM-V medium (Invitrogen, Burlington, ON, CA. Cat. No.12055-091). All cell lines were maintained in an incubator at $37^{\circ} \mathrm{C}$ with $5 \% \mathrm{CO}_{2}$ and $95 \%$ humidity.

\section{Neem Leaf Extraction}

Dried Neem leaf powder (Lot\# PRM03042104PD) was obtained from Premier Herbal Inc. (Toronto, ON, Canada). The leaf powder was extracted in either boiled double distilled water $\left(\mathrm{ddH}_{2} \mathrm{O}\right)$ or $100 \%$ anhydrous ethanol in a 1:10 ratio ( $1 \mathrm{~g}$ leaf powder to $10 \mathrm{~mL}$ anhydrous ethanol or $\mathrm{ddH}_{2} \mathrm{O}$ ). The ethanol extraction was carried out on a shaker at room temperature overnight, while the water extraction was completed in three hours on low heat. The water extract then undergoes gravity filtration with a P8 coarse filter, followed by vacuum filtration with a $0.45 \mu \mathrm{m}$ filter (PALL Life Sciences, VWR, Mississauga, ON. CA. Cat. No. 28148-028). The solvent from the ethanolic extract was evaporated using a RotorVap at $40^{\circ} \mathrm{C}$ and reconstituted in dimethylsulfoxide $\left(\mathrm{Me}_{2} \mathrm{SO}\right)$ at a final stock concentration of $500 \mathrm{mg} / \mathrm{ml}$. The extract was then passed through an Acrodisc $\AA 0.2 \mu \mathrm{m}$ DMSO-safe syringe filter (PALL Life Sciences, VWR, Mississauga ON, CA. Cat No. 28144-050) in a biosafety cabinet. For the water extract, the extract is frozen at $-80^{\circ} \mathrm{C}$, freeze dried using a lyophilizer and then reconstituted in $\mathrm{ddH}_{2} \mathrm{O}$ for a final stock concentration of $100 \mathrm{mg} / \mathrm{mL}$. Prior to use, the water extract is passed through a $0.22 \mu \mathrm{m}$ filter (Sarstedt, Montreal, QC, CA Cat No. 83.1826.001) in a biosafety cabinet.

\section{WST-1 Cell Viability Assay}

To assess the effects of Neem leaf extracts on cancer cell viability, equal amounts of cells (E6-1, HT-29, NHFs, ncPBMCs or NCM460) were plated in a 96well clear bottom tissue culture plate and treated with increasing concentrations of either the aqueous or ethanolic NLE for 48 and 96 hours. Following treatment, cells were incubated with a water-soluble tetrazolium salt dye (WST-1) (Roche Applied Science, Indianapolis, IN, USA. Cat. No.5015944001), for four hours at $37^{\circ} \mathrm{C}$ and $5 \%$ $\mathrm{CO}_{2}$. Metabolically active cells express extracellular enzymes, which are able to cleave the WST-1 into a coloured formazan product. The formazan product was then quantified by taking absorbance readings at a wavelength of $450 \mathrm{~nm}$ using a SpectraMax M3 Multi-Mode microplate reader (Molecular Devices, Sunnyvale, CA, USA). Results are statistically analyzed using the GraphPad 5.0 Prism software and expressed as a percent of the control.

\section{Cell Death Quantification}

To assess the selectivity of NLEs, equal amounts of primary peripheral blood mononuclear cells were obtained from healthy patients as described above and equal amounts were seeded into a 6-well plate. The cells were then treated with NLEs for 48 hours. Following treatment, cells were collected and washed twice in PBS. Cells were then resuspended in PBS and $1 \mathrm{mg} / \mathrm{mL}$ of propidium iodide (PI) (Life Technologies, Burlington, ON, CA, Cat. No. P3566) was added and incubated for $10 \mathrm{~min}$ at $37^{\circ} \mathrm{C}$. Cells were quantified and sorted using the Countess ${ }^{\circledR}$ II FL automated cell counter (Life Technologies, Burlington, ON, CA) which distinguished PI positive cells from PI negative cells. Results were analyzed using the GraphPad 5.0 Prism software. The Countess ${ }^{\circledR}$ was also used to capture brightfield and fluorescent images of the cells at various fields under $16 \mathrm{x}$ magnification.

\section{Cellular Staining for Programmed Cell Death}

To analyze the mode of cell death, cells are plated and treated for a defined period of time. After treatment, cells were stained with $10 \mu \mathrm{M}$ of Hoechst 33342 (Life Technologies, Burlington, ON, CA, Cat No. H3570) and $1 \mathrm{mg} / \mathrm{mL}$ of propidium iodide (PI) and incubated for $10 \mathrm{~min}$ at $37^{\circ} \mathrm{C}$. The cells were then examined under a fluorescent microscope (Leica DM IRB, Germany) and pictures were taken 
from five different fields at $10 \mathrm{x}$ and $400 \mathrm{x}$ magnification. Hoechst allows for the visualization of nuclear condensation while PI intercalates into exposed DNA allowing for differentiation between viable and non-viable cells.

To access the prevalence of apoptotic cells, Annexin-V stain binds to phosphatidylserine which characteristically becomes exposed on the outer membrane of the cell during apoptosis. Cells were grown and treated for a defined period of time and then collected. Once the cells were collected, they were washed with phosphate buffer saline (PBS) and then resuspended in Annexin- $\mathrm{V}$ binding buffer (10 $\mathrm{mM}$ HEPES/NaOH pH 7.5, $140 \mathrm{mM} \mathrm{NaCl}, 2.5 \mathrm{mM}$ $\mathrm{CaCl} 2$ ), containing 1:20 Annexin-V Alexa Fluor 488 conjugate (Life Technologies, Burlington, ON, CA, Cat. No. A13201) for $15 \mathrm{~min}$ at room temperature. The cells were then examined under a fluorescent microscope (Leica DM IRB, Germany) and pictures were taken at five different fields at 10x and 400x magnification. Cells were quantified and sorted using the Countess ${ }^{\circledR}$ II FL automated cell counter (Life Technologies, Burlington, ON, CA) which distinguished Annexin and PI positive cells from negative cells. Results were analyzed using the GraphPad 5.0 Prism software.

\section{JC-1 Staining}

To monitor the dissipation of the mitochondrial membrane potential of treated cells, JC-1 dye (5,5,6,6'-tetrachloro-1,1',3,3'-tetraethy

lbenzimidazolylcarbocyaninechloride) (Invitrogen, Burlington, ON CA, Cat No. T3168) was used. Cells were grown and treated for 24 hours and incubated with $\mathrm{JC}-1$ dye for 45 minutes at $37^{\circ} \mathrm{C}$. Stained cells were viewed using a fluorescent microscope and pictures were taken at five different fields. In viable cells, with intact mitochondria, JC-1 accumulates as aggregates and fluoresces red. In apoptotic and necrotic cells, with dissipated mitochondrial membrane potential, JC-1 does not accumulate in the mitochondria and shifts from the red form to the monomeric green form.

\section{Whole Cell ROS Measurement}

To analyze ROS production in whole cells, E6-1 cells were treated with aqueous or ethanolic NLE for a designated period of time. Following treatment, the cells were collected and incubated with 2',7'dichlorodihydrofluorescein diacetate $\left(\mathrm{H}_{2} \mathrm{DCFDA}\right)$
( Life Technologies, Burlington, ON, CA. Cat. No.D399) for one hour at $37^{\circ} \mathrm{C}$. Following incubation, $200 \mathrm{uL}$ of cell solution was added to an opaque bottom, 96-well tissue culture plate. Fluorescence readings were taken every 5 minutes for a total time of 5 hours; Ex. $560 \mathrm{~nm}$ and Em. 590 $\mathrm{nm}$, on a spectrofluorometer (SpectraMax Gemini XS, Molecular Devices, Sunnyvale, CA). The readings were analyzed using GraphPad Prism 5.0 software and expressed as relative fluorescence units (RFU) per 10000 cells.

\section{Mitochondrial Isolation and Measurement of ROS Production}

To measure ROS production, mitochondria were isolated from untreated E6-1 or HT-29 cells. Cells were washed twice in cold PBS, resuspended in hypotonic buffer (1 mM EDTA, $5 \mathrm{mM}$ Tris- $\mathrm{HCl}$, $100 \mathrm{mM}$ mannitol, $70 \mathrm{mM}$ sucrose, $10 \mu \mathrm{M}$ Leu-pep, $10 \mu \mathrm{M}$ Pep-A, and $100 \mu \mathrm{M}$ PMSF) and immediately homogenized, and centrifuged at $600 \times \mathrm{g}$ for 5 minutes at $4^{\circ} \mathrm{C}$. The supernatant was centrifuged at $15,000 \times \mathrm{g}$ for 15 minutes at $4^{\circ} \mathrm{C}$. The resulting cytosolic supernatant was discarded and the mitochondrial pellet was resuspended in cold hypotonic buffer. To measure ROS levels, Amplex Red (Molecular Probes, Eugene, OR, USA. Cat. No.A12222) was used. The isolated mitochondria were resuspended in cold hypotonic buffer and 150 $\mu \mathrm{g}$ of protein was added to wells of a 96-well opaque plate. Cells were treated with ethanolic or aqueous NLE and as a positive control, $250 \mu \mathrm{M}$ paraquat (Sigma Aldrich, Mississauga, ON, CA. Cat. No.75365-730) was used for treatment. Amplex Red reagent was added to each well for a final concentration of $50 \mu \mathrm{M}$; horseradish peroxidase (HRP) was added in the ratio of 6 units per $200 \mu \mathrm{L}$. Fluorescence readings were taken every 5 minutes for a total time of 5 hours at Ex. $560 \mathrm{~nm}$ and Em. 590 $\mathrm{nm}$ on a spectrofluorometer (SpectraMax Gemini XS, Molecular Devices, Sunnyvale, CA). The readings were analyzed using GraphPad Prism 5.0 software and expressed as relative fluorescence units (RFU).

\section{Western Blot Analysis}

Cells were treated for 1, 6, 24 and 48 hours and lysed following treatment with $0.1 \%$ NP40 lysis buffer (0.1\% (v/v) NP40, $20 \mathrm{mM}$ Tris HCl, $100 \mathrm{mM} \mathrm{NaCl}$, $5 \mathrm{mM}$ EDTA, $10 \mu \mathrm{M}$ Leu-pep, $10 \mu \mathrm{M}$ Pep-A, and 
$100 \mu \mathrm{M}$ PMSF). Protein samples were subjected to SDS-PAGE, transferred onto a nitrocellulose membrane, and blocked with $5 \% \mathrm{w} / \mathrm{v}$ milk in TBST (Tris-Buffered Saline Tween-20) solution for 1 hour. Membranes were then incubated overnight at $4{ }^{\circ} \mathrm{C}$ with either superoxide dismutase (SOD1) monoclonal antibody $(1: 1000)$ raised in mice (Novus Biologicals, Oakville, ON, CA, Cat.No. NBP147443 ,) or Catalase polyclonal antibody $(1: 1000)$ raised in rabbits (Novus Biologicals, Oakville, ON, CA. Cat. No. NBP2-24916), prepared in $2 \% \mathrm{w} / \mathrm{v}$ milk in TBST. After overnight incubation, the membranes were washed in TBST and then incubated for one hour at room temperature with anti-mouse or anti-rabbit secondary antibody (1:2000) conjugated to horseradish peroxidase (Abcam, Cambridge, MA, USA, Cat. No. ab6728, ab6802, respectively). Membranes that were to be incubated with Glut9 polyclonal antibody (Novus Biologicals, Oakville, ON, CA, Cat.No. NBP106271) were first blocked with $10 \%$ bovine serum albumin (BSA) for 1 hour at room temperature followed by overnight incubation at $4{ }^{\circ} \mathrm{C}$ with Glut9 antibody $(1: 1000)$ raised in mice prepared in $10 \%$ BSA. Following incubation the membrane was washed with 10\% BSA followed by washes in TBST. After the final wash, the membrane was incubated with anti-mouse secondary antibody (1:2000) conjugated to horseradish peroxidase prepared in $10 \%$ BSA. Following secondary antibody incubation, the membranes where rinsed with TBST followed by three five minutes washes and were then visualized with VisiGlo $^{\text {TM }}$ Select HRP chemiluminescent substrate (Amresco, Solon, OH, USA Cat No. 1B1583). Densitometry analysis was conducted using the ImageJ software and fold increase with respect to the control was analyzed using GraphPad 5.0 Prism software.

\section{HPLC Analysis of Neem Leaf Extracts}

Neem extracts (aqueous and ethanolic extracts) were redissolved in 40:40:20 methanol:acetonitrile:water at $10 \mathrm{mg} / \mathrm{mL}$, followed by vortex mixing and sonication for $5 \mathrm{~min}$ and filtration through 0.2 micron syringe filters. Characterization of neem aqueous and $80 \%$ ethanol extracts were done based on a previously published protocol (30) with minor modifications. Briefly, the analytical system consisted of an 1100 series HPLC-DAD system (Agilent Technologies, Paulo Alto, CA, USA).
Separations were performed on a $100 \times 2 \mathrm{~mm}$ ID, 3 micron particle size YMC C18 column (Waters Inc. Broussard, MT, USA). Mobile phase consisted of A= $\mathrm{H}_{2} 0, \mathrm{~B}=$ acetonitrile, each supplemented with $0.1 \%$ formic acid. Linear gradient of $10-80 \%$ B was applied in $30 \mathrm{~min}$ at a flow rate of $0.5 \mathrm{~mL} / \mathrm{min}$ and column thermostat temperature of $65^{\circ} \mathrm{C}$. Diode array detection of the extracts and standard compounds were within the range of 210-380 $\mathrm{nm}$. Identification of compounds was based on metabolomics library matching and quantification was based on cochromatography with authentic compounds.

\section{In vivo Assessment}

Six week old immunocompromised CD1 nu/nu mice were obtained from Charles River Laboratories. The mice were housed in laboratory conditions of a 12hour light/dark cycle, in accordance with the animal protocols outlined in the University of Windsor Research Ethics Board protocol AUPP\# 14-15. Following an acclimatization period of one week, mice were injected subcutaneously with a colon cancer suspension in PBS at a concentration of $2.0 \times 10^{6}$ cells per mouse (HT-29 p53 -/- in the left flank). Once tumours were formed, mice were randomly separated into two groups (3 animals/untreated control, 4 animals/treatment group). The untreated control group was given plain filtered water, while the treatment group received 5.0 $\mathrm{mg} / \mathrm{mL}$ of aqueous NLE in filtered water for 47 days. Tumour volumes and body weights of the mice were measured throughout the length of the study.

\section{STATISTICAL ANALYSIS}

All experiments were repeated three independent times, unless specified and the statistical analysis was done using the GraphPad 5.0 Prism software. To test for statistical significance, the student's t-test and a two-way analysis of variance (ANOVA) was used followed by a post hoc Bonferroni's multiple comparisons test to analyze significance compared to the control. A value of $\mathrm{p}<0.05$ was considered significant. Where applicable, replicate values were expressed as a mean \pm the standard error of the mean (SEM). 


\section{RESULTS}

Neem Leaf Extracts Cause a Reduction in Viability in Cancerous Cells with Minimal Toxicity to Normal Cells

We focused on the aggressive colorectal cancer (HT29) and Acute T cell leukemia (E6-1) cells, as the cancer cell models, for the assessment of the anticancer activity of Neem leaf extracts and normal human fibroblasts (NHFs) and normal colon mucosal epithelial cells (NCM460), as a non-cancerous counterpart. These cells were treated with either aqueous or ethanolic Neem leaf extracts (NLEs) at increasing doses and time periods and evaluated for cell viability using the WST-1 metabolic assay. The results show a decrease in the absorbance of formazan, a product indicative of metabolically active cells, with an increase in concentration and time of exposure of both aqueous and ethanolic NLEs. This reduction in viability was observed in both leukemia (E6-1) and colon (HT-29) cancer cells (Figure 1A-D). The effective concentration (EC-50) for ethanolic NLE is $0.04 \mathrm{mg} / \mathrm{mL}$ in leukemia cells (Figure 1A) and $0.4 \mathrm{mg} / \mathrm{mL}$ in colon cancer cells (Figure 1C). On the other hand, the EC-50 of aqueous NLE in leukemia and colon cancer cells is $0.5 \mathrm{mg} / \mathrm{mL}$ (Figure 1B) and $3.0 \mathrm{mg} / \mathrm{mL}$ (Figure 1D), respectively. In parallel, normal cells were treated with NLEs and assessed for selectivity of these extracts to cancer cells. No significant reduction in the cell viability was exhibited in non- cancerous cells treated with similar doses (Figure 1E-H). To further assess the possible toxicity on human blood cells, Neem leaf extracts were tested on peripheral blood mononuclear cells (PBMCs), obtained from healthy volunteers. The results indicate that these cells were tolerant to the NLEs (Figure 2A and 2B). Image-based cytometry was employed to quantify the dead and live cells using propidium iodide. Results shown in Figure 2C-D indicated that there was no significant difference in the number of dead cells in NLE treated cells, as compared to the untreated control.

\section{Induction of Apoptosis in Cancer Cells Treated with Neem Leaf Extracts}

To determine if the reduction in viability observed with the WST-1 assay was due to cytotoxicity or cytostatic effects of NLEs, fluorescence microscopy with Hoechst, propidium iodide (PI) and the apoptotic marker Annexin V were used. These dyes allowed us to determine if cell death was induced, and whether it was apoptosis or necrosis. Following treatment for 48 hours, we observed an increase in bright Hoechst staining, indicative of chromatin condensation, a characteristic of apoptosis, in E6-1 and HT-29 cells treated with NLEs (Figure 3A-D). In addition, these figures show a clear increase in Annexin-V positive cells, indicating that cells are exhibiting the morphological characteristics of apoptosis. The presence of PI positive cells in Figures 3A-D is attributed to necrotic-like morphology which results in cell culture when cells undergo the later stages of apoptosis. In contrast, similar treatments in NHF cells, did not show apoptosis or cell death (Figure 3E-F) except at higher doses (Figure 3E-F, last column). Furthermore, image-based cytometry was used to quantify the percentage of apoptosis occurring in these cancer cells. The results show a drastic increase in the percentage of apoptotic cells in samples treated with the ethanolic extract of NLE and a minimal increase in the same process with the aqueous extract (Figure $3 \mathrm{G})$. These findings confirm the efficacy of NLEs as possible anticancer agents.

\section{Neem Leaf Extracts Cause Mitochondrial Membrane Permeabilization}

Since the mitochondria are often key players in the progression and execution of apoptosis, we further assessed mitochondrial integrity following NLE treatment. The cationic dye, JC-1, aggregates in healthy, intact mitochondrial and fluoresces red. When the mitochondrial potential is collapsed the aggregation is lost and the dye is diffused. After 24 hours of treatment with NLEs, a decrease in red fluorescence is observed in cancer cells incubated with JC-1 dye (Figure 4). This decrease occurs in a dose-dependent manner, as red fluorescence continues to decrease with increasing dose.

NLE Treatment Caused Increased Production of
ROS in Leukemia Cells and in Isolated
Mitochondria
Mitochondrial permeabilization can result from a
number of factors, including oxidative stress.




\section{Ethanolic NLE}

A

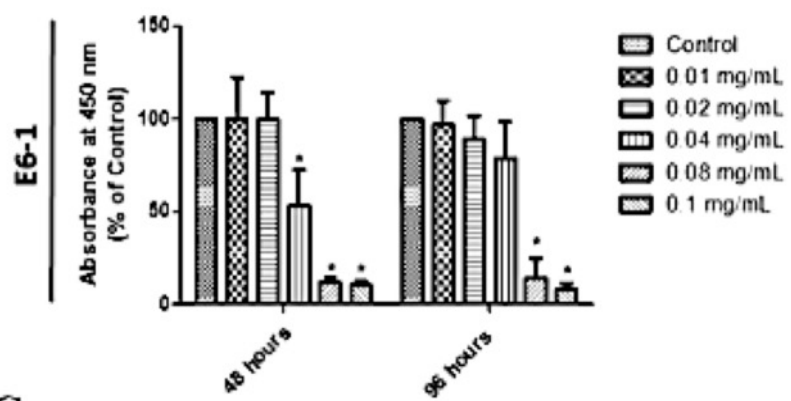

C

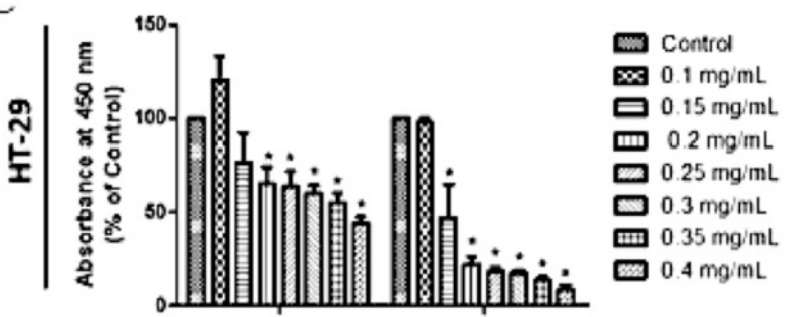

E
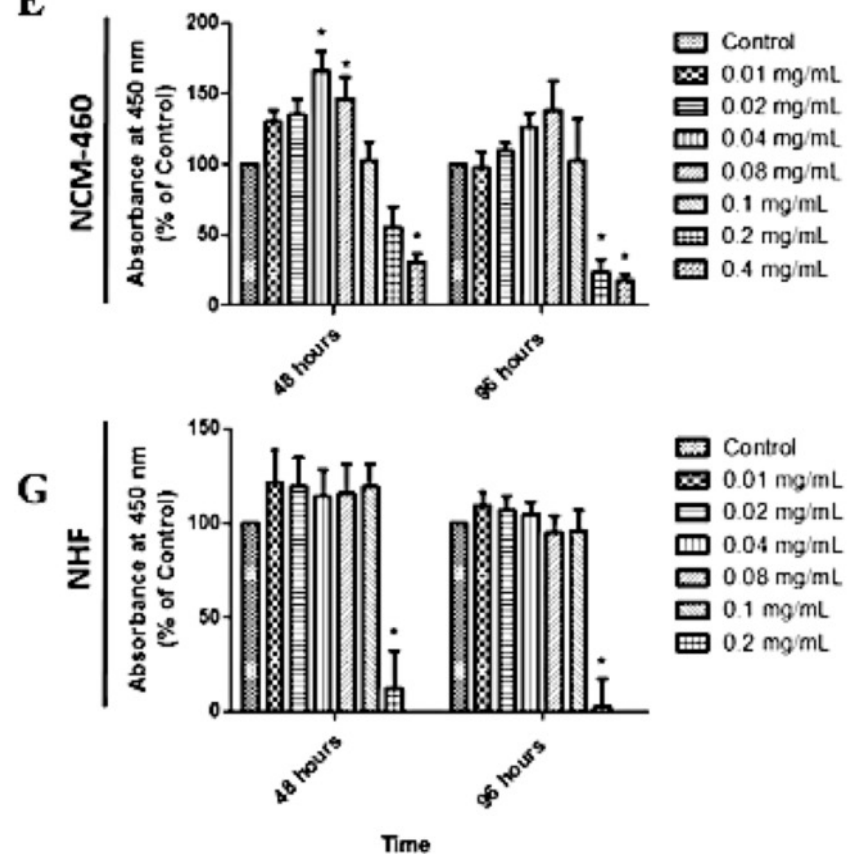

B

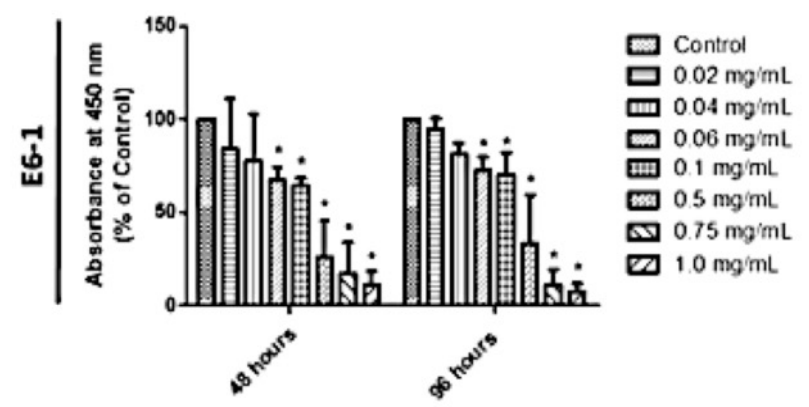

D

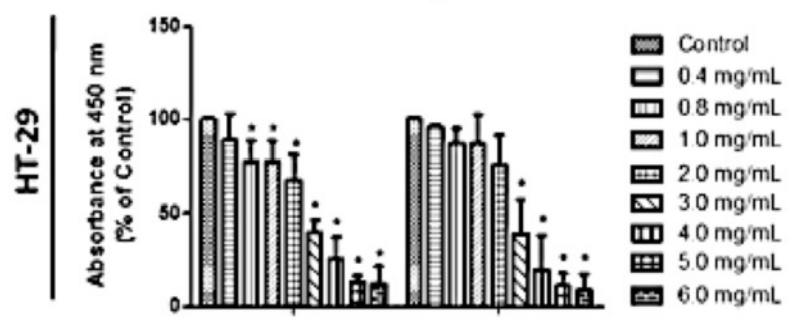

F

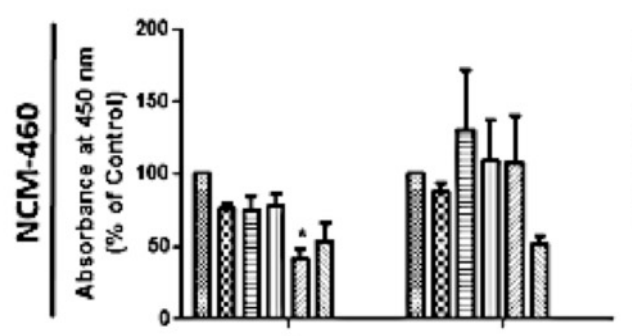

H
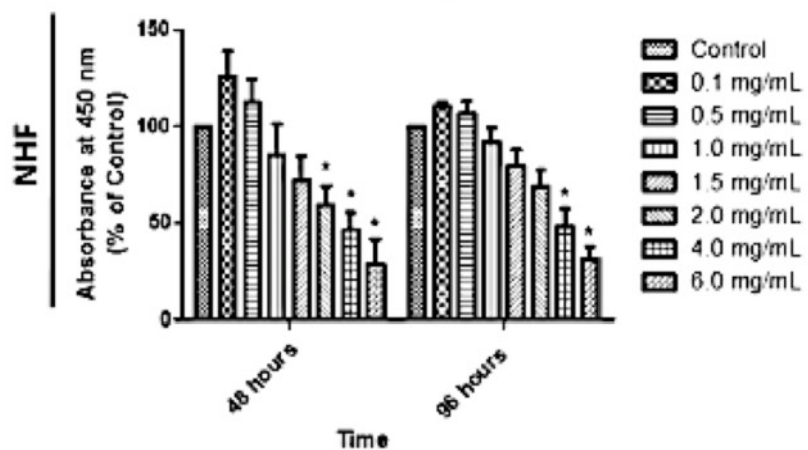

Control

एo. $0.5 \mathrm{mg} / \mathrm{mL}$

D $1.0 \mathrm{mg} / \mathrm{mL}$

뜨 $2.0 \mathrm{mg} / \mathrm{mL}$

Ca. $4.0 \mathrm{mg} / \mathrm{mL}$

$6.0 \mathrm{mg} / \mathrm{mL}$

Figure 1. Neem leaf extracts (NLEs) reduce the viability of cancerous cells with minimal toxicity to normal cells. E6-1 leukemia cells (A,B) and HT-29 colon cancer cells (C,D) were treated with increasing doses of either ethanolic or aqueous NLE and cellular viability was quantified using a WST-1 dye. Absorbance was measured at $450 \mathrm{~nm}$ and expressed as a percent of the control. Normal colon mucosal epithelial cells (NCM-460) (E, F) and normal human fibroblasts (NHF) (G,H) were also treated with NLE and viability was measured as previously mentioned. All values are expressed as a mean \pm SEM from three independent trials. ${ }^{*} \mathrm{p}<0.05$ vs. control. 

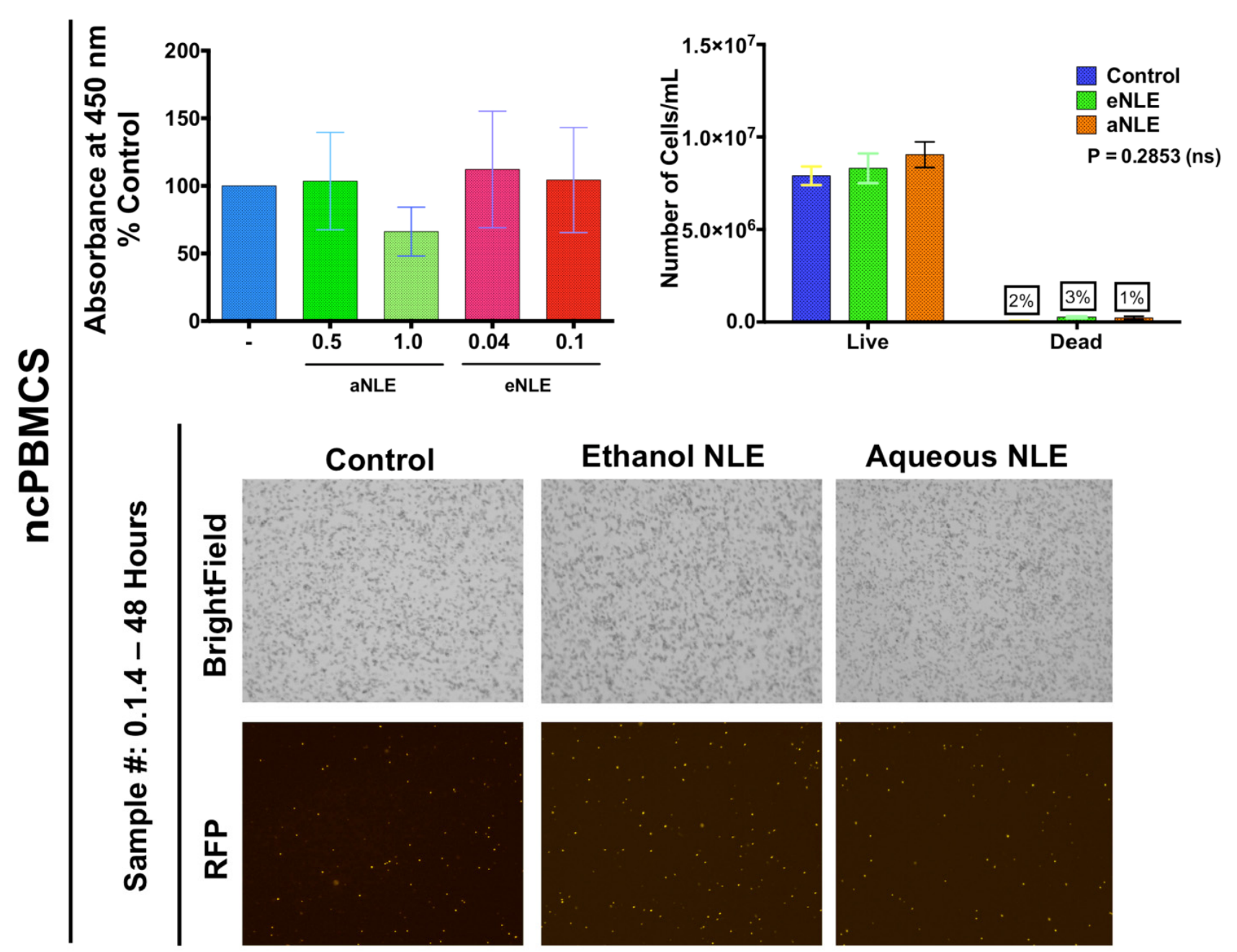

Figure 2. Neem leaf extracts (NLEs) are not cytotoxic to non-cancerous primary peripheral blood mononuclear cells (ncPBMCs). Non- cancerous PBMCs were taken from the blood of healthy volunteers and treated with ethanolic and aqueous NLE for 48 hours. Viability was quantified using a WST-1 dye where absorbance was measured at $450 \mathrm{~nm}$ and expressed as a percent of the control (A) and a trypan blue exclusion assay (B). Values are expressed as a mean \pm SEM from samples from three separate volunteers. The ncPMCs from one volunteer were stained with propidium iodide and a Countess ${ }^{\circledR}$ image based cytometer was used to differentiate and quantify living and dead cells and dead cells were expressed as a percent of the total cells (C).

Considering this, it is of considerable interest to measure levels of ROS in NLE treated cancer cells, which have exhibited permeabilized mitochondria. As described in the materials and methods, leukemia cells were treated with NLEs or the positive control Paraquat for 48 hours and incubated with the oxidative stress marker, $\mathrm{H}_{2}$ DCFDA to detect ROS levels via green fluorescence. Treatment of leukemia cells with ethanolic or aqueous NLE caused an increase in whole cell ROS levels greater than the control (Figure 5A-B). To better analyze the role of oxidative stress in the mitochondria and to further pursue the hypothesis that the mitochondria are a direct target of NLEs, ROS levels in isolated mitochondria were measured. Mitochondria were isolated from E6-1 leukemia cells and were treated with ethanolic NLE or Paraquat and mitochondrial ROS levels were measured as mentioned above. Results in Figure 6 show that like in the whole cell, ethanolic NLE also causes an increase in mitochondrial ROS. These results indicate that oxidative stress may play a role in NLE induced mitochondrial instability of cancer cells, leading to the subsequent induction of apoptosis. 
Ethanolic NLE

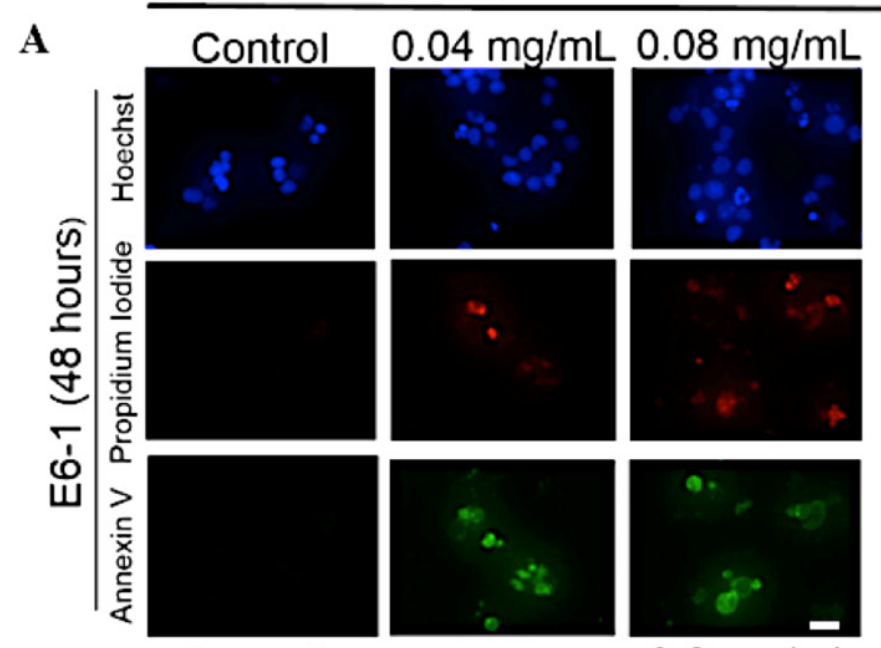

C

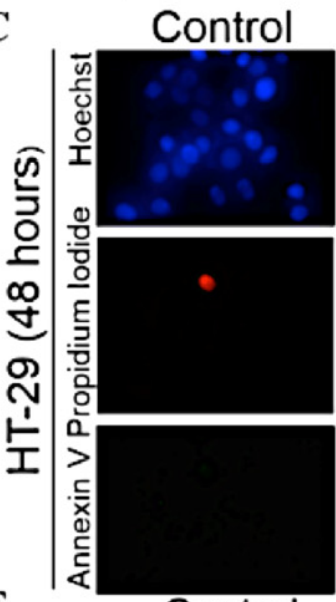

$\mathbf{E}$

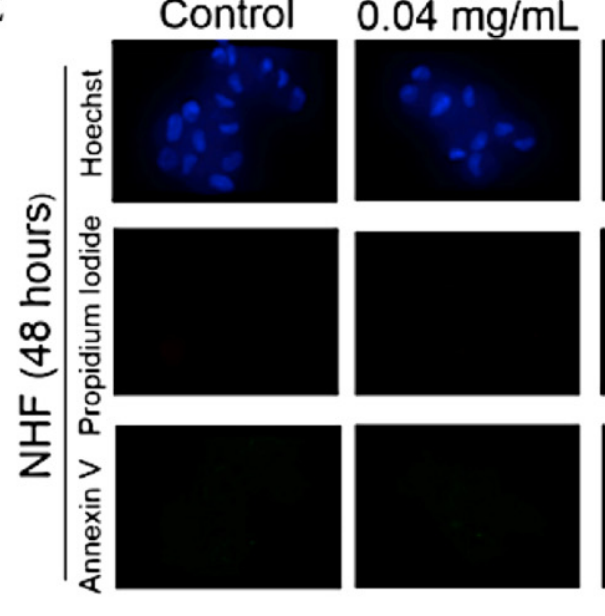

$0.2 \mathrm{mg} / \mathrm{mL}$
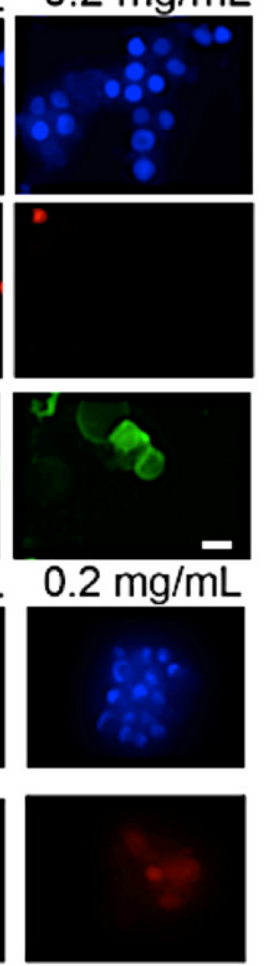

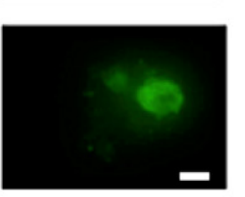

Aqueous NLE
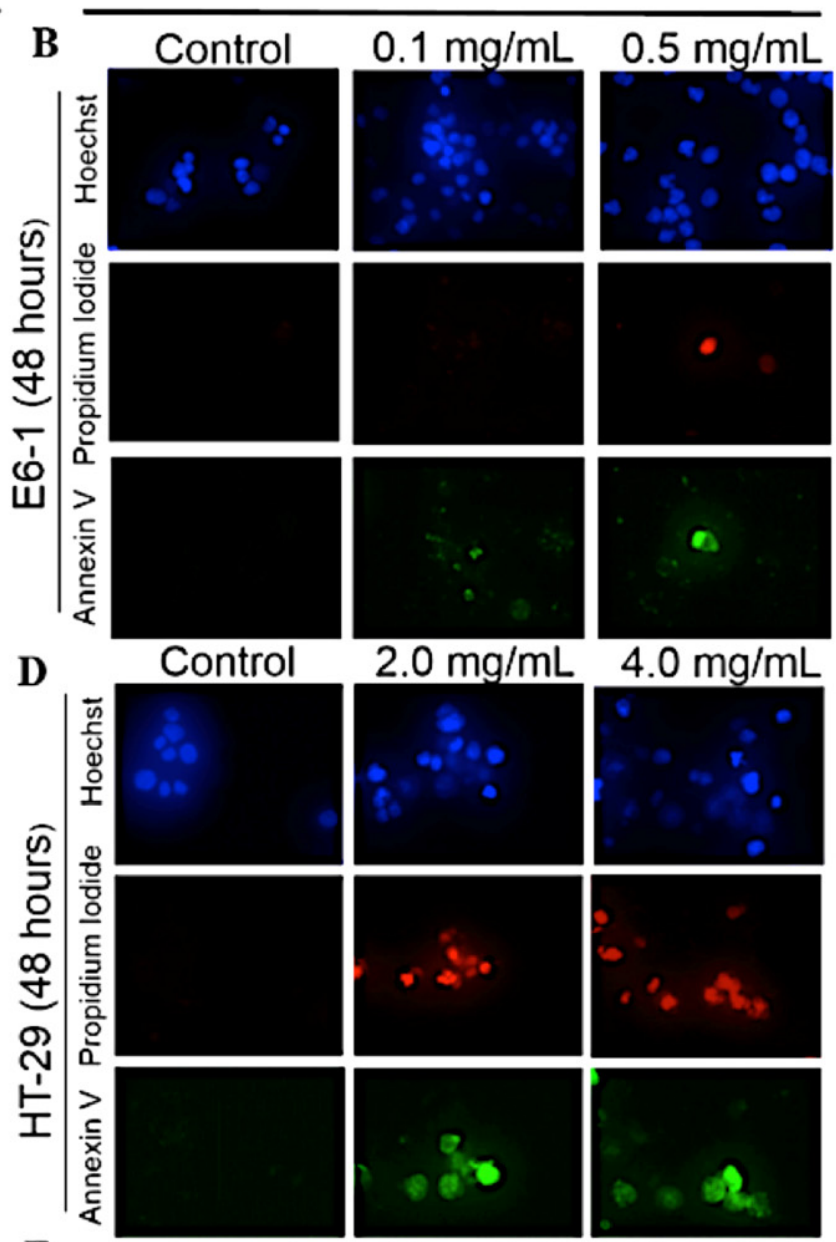

$2.0 \mathrm{mg} / \mathrm{mL}$
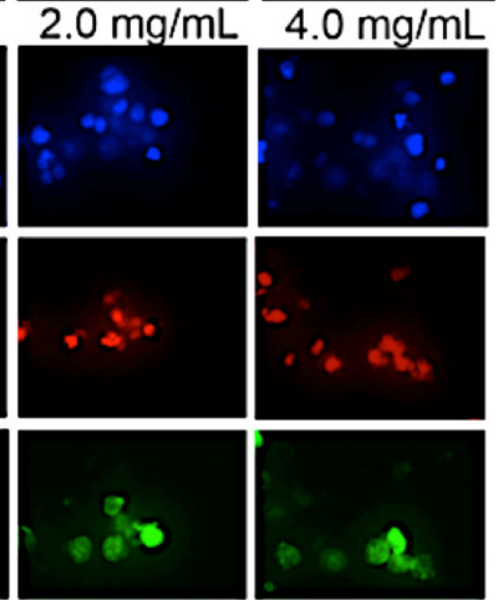

F

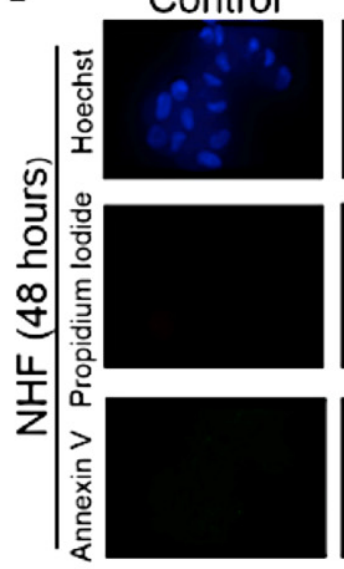

$2.0 \mathrm{mg} / \mathrm{mL}$
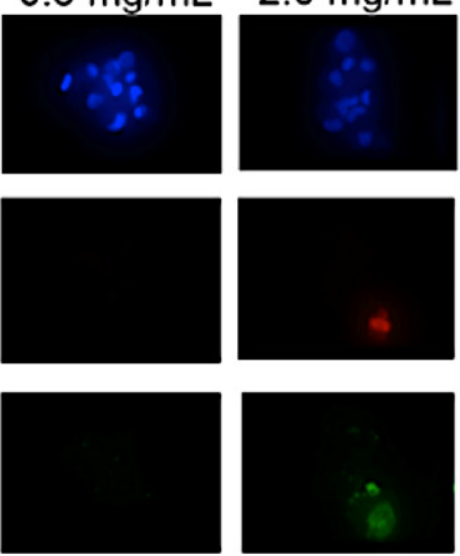

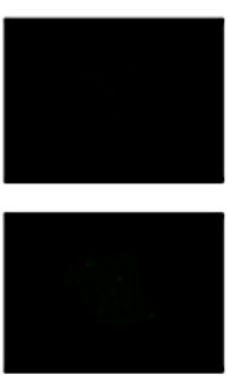

Figure 3 - (A to F) 
Figure 3. Continued.....

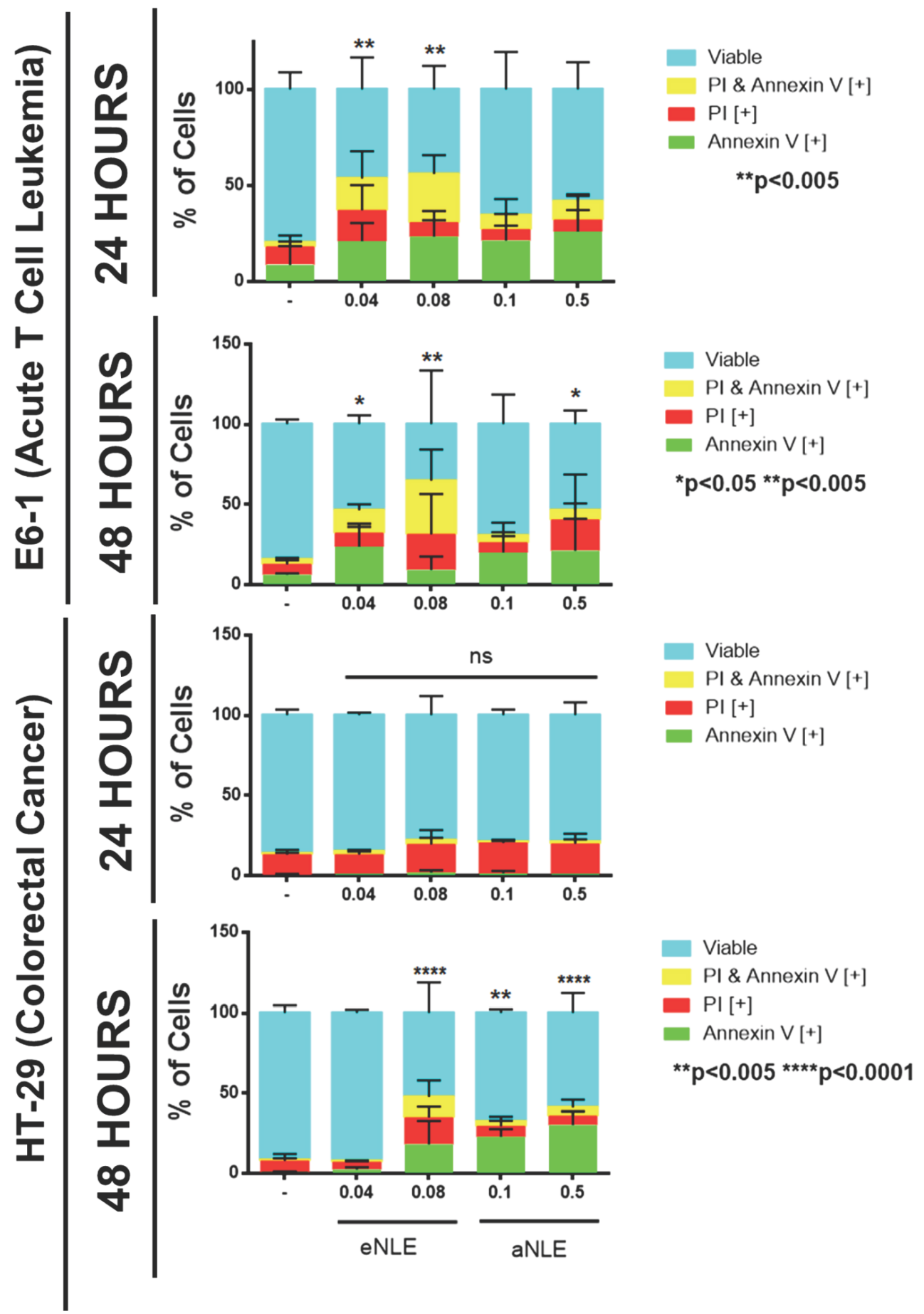

Figure 3. NLE induces apoptotic cell death in cancer cells. Following treatment with either ethanolic (A, C, E) or aqueous (B, D, F) NLE for 48 hours, HT-29 colon cancer and E6-1 leukemia cells were stained with Hoechst dye to assess nuclear morphology. The cells were also stained with propidium iodide to analyze cellular viability and Annexin-V to detect apoptotic cells and visualized under a fluorescence microscope at 400x magnification. Images are representative of three independent trials. Scale bar $=25 \mu \mathrm{m}$. (G) Cell death was quantified using a Countess ${ }^{\circledR}$ image based cytometer, following staining with Annexin- $\mathrm{V}$ and Propidium iodide. All values are expressed as a mean $\pm \mathrm{SEM}$ from three independent trials. 


\section{Ethanolic NLE}
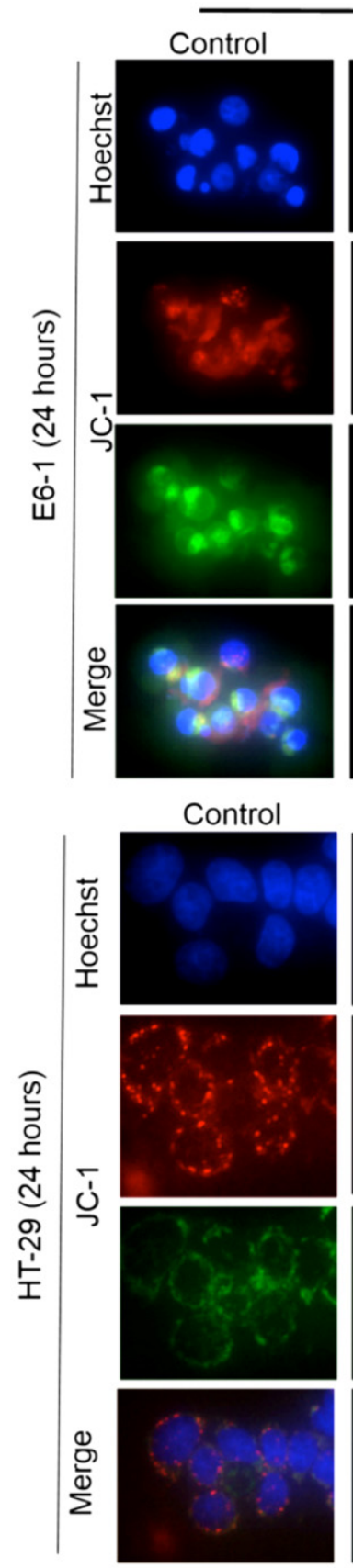
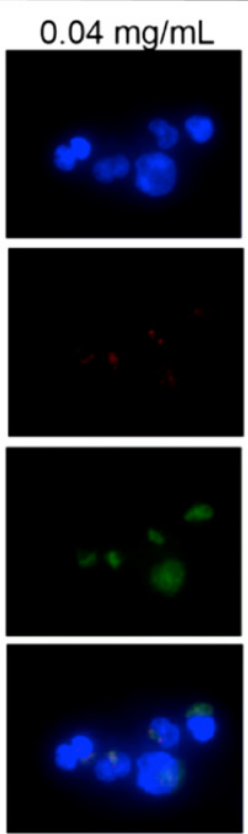

$0.08 \mathrm{mg} / \mathrm{mL}$
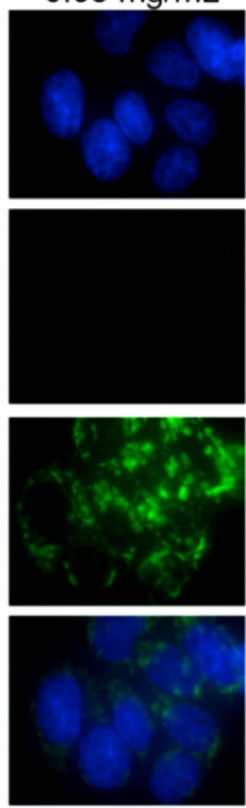
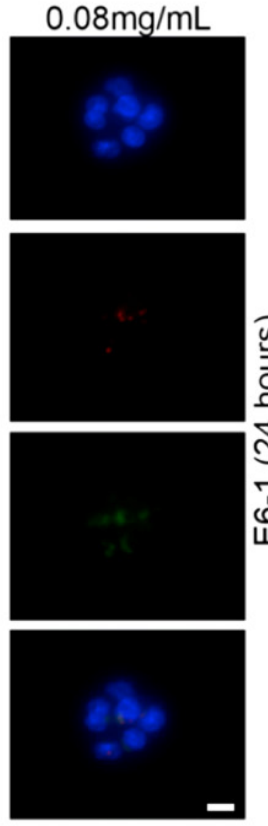

$0.2 \mathrm{mg} / \mathrm{mL}$
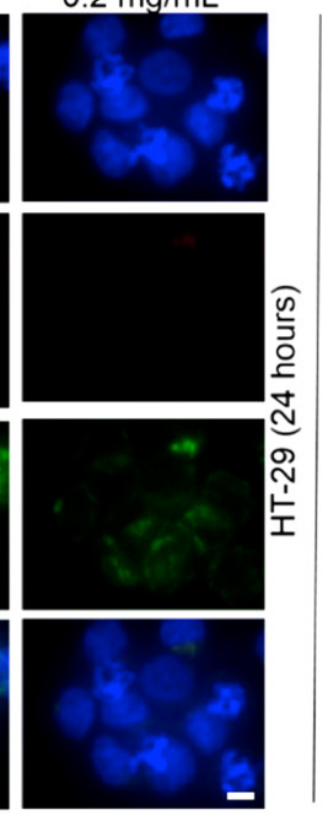

Aqueous NLE

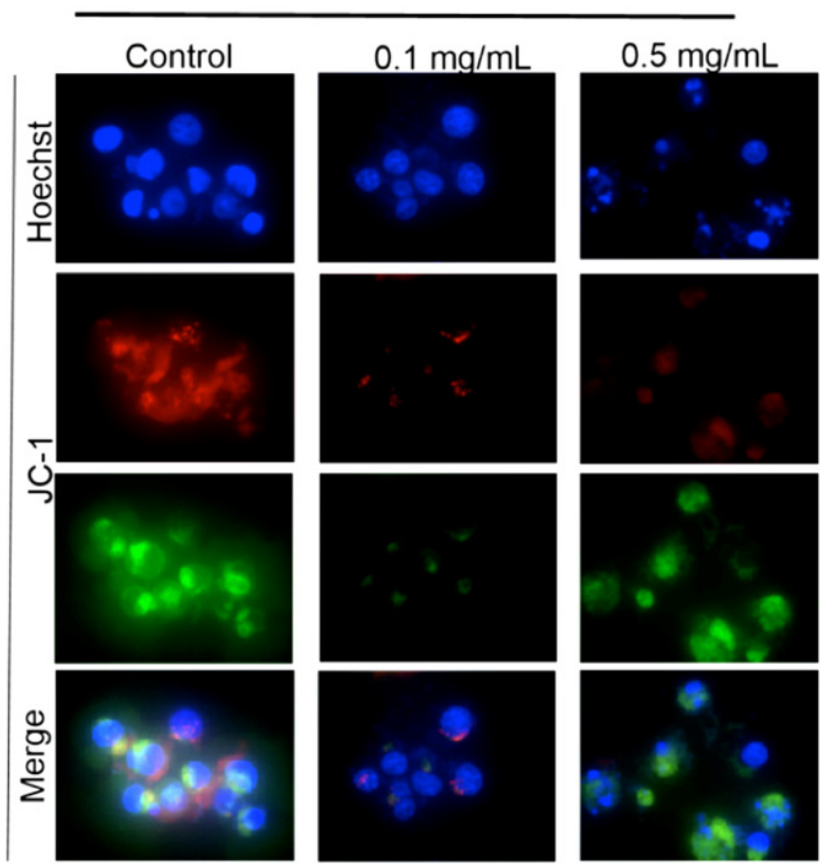

$2.0 \mathrm{mg} / \mathrm{mL}$
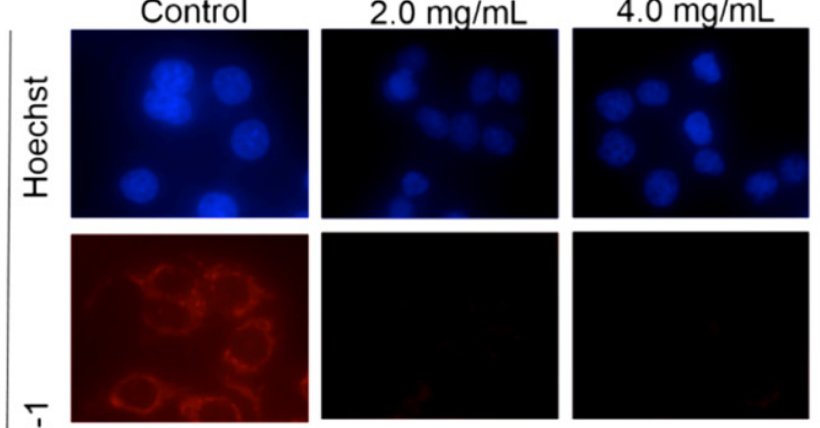

ভ̇
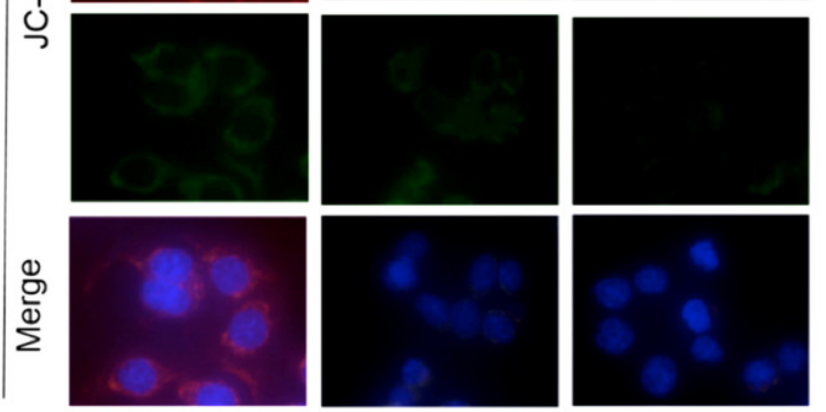

Figure 4. Neem leaf extracts cause destabilization of cancer cell mitochondria. HT-29 colon cancer cells (A,B) and E61 leukemia cells (C,D) were treated with aqueous or ethanolic NLE for 24 hours and then incubated with the mitochondrial membrane permeable dye, JC-1. Fluorescence microscopy at 400x magnification was used to evaluate the levels of green monomeric versus red polymeric JC-1 dye while Hoechst dye was used to assess nuclear morphology. Images are representative of three independent trials. Scale bar $=25 \mu \mathrm{m}$. 

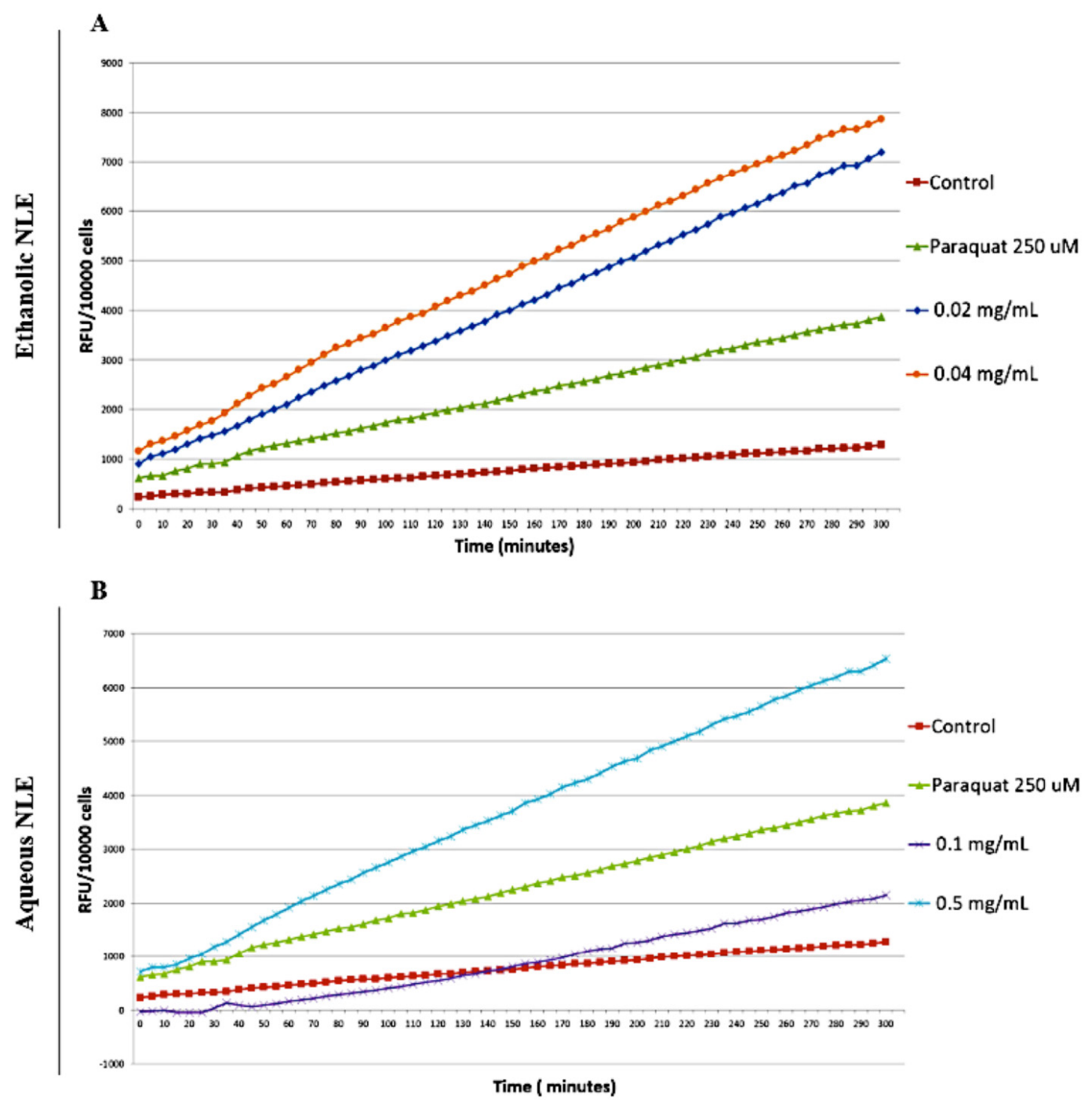

Figure 5. Cancer cells treated with aqueous and ethanolic NLE exhibit increased cellular levels of ROS. E6-1 leukemia cells were treated with aqueous or ethanolic NLE for 48 hours. Paraquat treated cells were used as a positive control, The cells were incubated with $\mathrm{H}_{2}$ DCFDA dye and ROS levels were monitored over a period of five hours by measuring levels of fluorescent $\mathrm{H}_{2}$ DCFDA using the SpectraMax Gemini XS spectrofluorometer. Results are representative of three independent trials.

\section{Effect of Neem Leaf Extracts on the Expression of Proteins Involved in Anti-oxidative Defense} The role of oxidative stress in NLE-induced cytotoxicity appears to be important. Since it was determined that NLE causes an increase in the production of ROS in cancer cells as well as in isolated mitochondria, levels of proteins involved in antioxidant response were assessed using Western blot analysis as described in Material and Methods. It was observed that ethanolic NLE causes a timedependent increase in levels of SOD and catalase (Figure 7A, B), however levels of Glut9 exhibited a slight time-dependent decrease (Figure 7C). Conversely, cells treated with aqueous NLE did not exhibit an increase in levels of SOD and catalase (Figure 7A,B), however a time-dependent transient increase in levels of Glut9 was seen at 1 hour and 6 hours of treatment (Figure 7C). The varied response to oxidative stress exhibited by ethanolic and aqueous NLE indicates that these two extracts might have differential effects and mechanisms of actions in cancer cells, especially as it pertains to the production of ROS. 


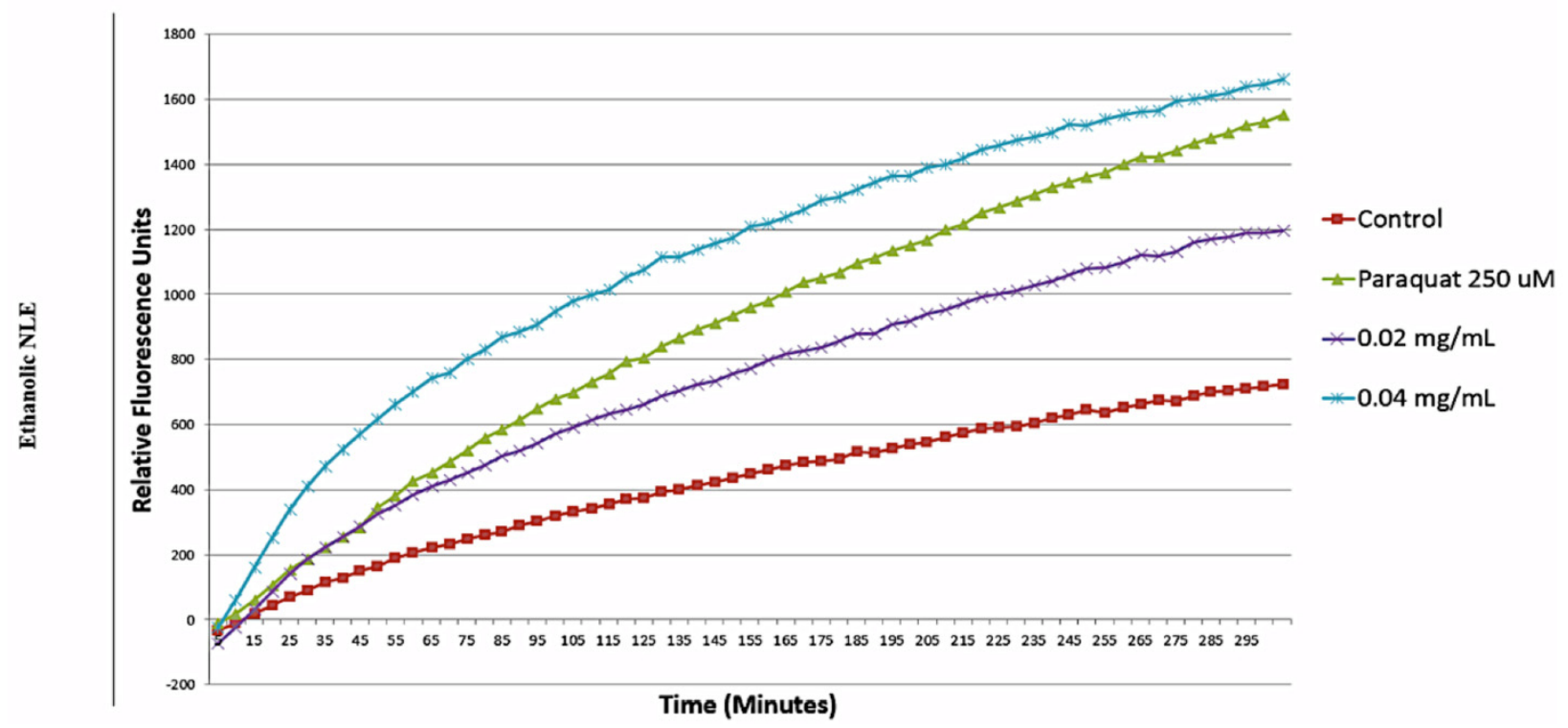

Figure 6. Ethanolic Neem leaf extract causes an increase in mitochondrial ROS. The mitochondria of leukemia cells (E6-1) were isolated and directly treated with ethanolic NLE. Paraquat treated mitochondria were used as a positive control. ROS levels were monitored for five hours after treatment with the use the fluorescent ROS marker, Amplex Red and the SpectraMax Gemini XS spectrofluorometer. Results are representative of three independent trials.

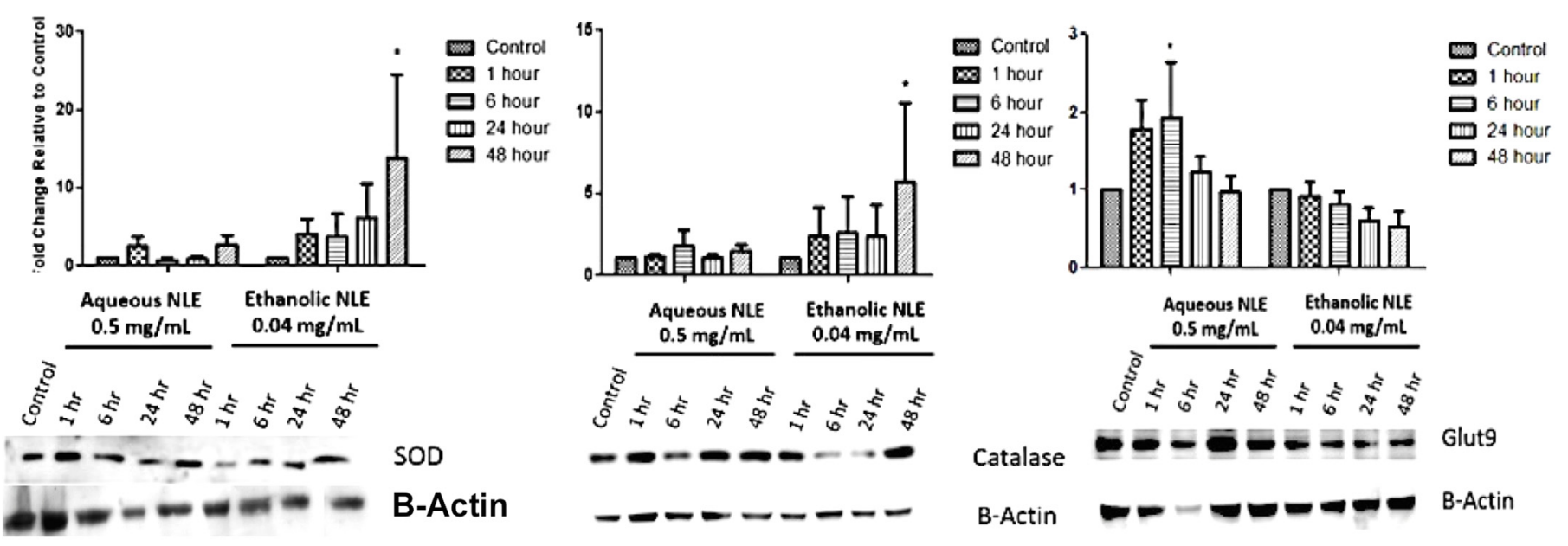

Figure 7. Neem leaf extracts alter levels of expression of antioxidant related proteins. E6-1 leukemia cells were treated for 1, 6, 24 and 48 hours with NLEs and lysed. Cell lysates were separated by SDS-PAGE, transferred to a nitrocellulose membrane and blotted for SOD, Catalase or Glut9 and each blot was stripped and probed for b-actin, as a loading control. Bands were visualized using VisiGlo ${ }^{\text {TM }}$ Select HRP Chemiluminescent Substrate. Data was analyzed using the Image-J and GraphPad Prism 5.0 software. Values are from three independent trials and expressed as a mean $\pm \mathrm{SEM}$. ${ }^{*} \mathrm{p}<0.05$

\section{Differential Profiles of Neem Leaf Extracts}

Following the assessment of ROS production by neem leaf extracts, it was observed that there was a differential response of both cancer cells to the production of ROS. These findings prompted the next phase of this study, which was to determine the differences between the aqueous and ethanolic extracts, based on the differences in their constituents. Using an analytical system of an HPLC-DAD set up, the different profiles of the ethanolic and aqueous extracts of neem leaf were obtained. Identification of compounds was based on 
metabolomics library matching and quantification was based on co-chromatography with authentic compounds (Figure 8). The aqueous extract showed a clear peak for luteolin, while the ethanolic extract had peaks for quercetin and rutin, with an unknown peak (still to be identified).

\section{Aqueous Neem Leaf Extract is Tolerated and} Effective in Animal Models After observing a strong and selective anti-cancer activity with in vitro assays, in vitro assessment of NLEs was conducted. Aqueous over ethanolic NLE was chosen as a treatment for easy extraction and oral delivery. To assess the activity of aqueous NLE in vivo, human xenograft tumours were injected in mice who then received oral administration of aqueous NLE in the material and methods Throughout the course of the study, body weights were recorded, as a measure of toxicity, and it was found that there was no significant difference between the weights of the control group versus the treated group. Tumour volumes were also measured and it was found that aqueous NLE led to a decrease in the growth rate of the tumours in this group (Figure 9). All of these findings further promote the appreciation for the possible role of Neem leaf extracts against both colorectal cancer and leukemia cell models.
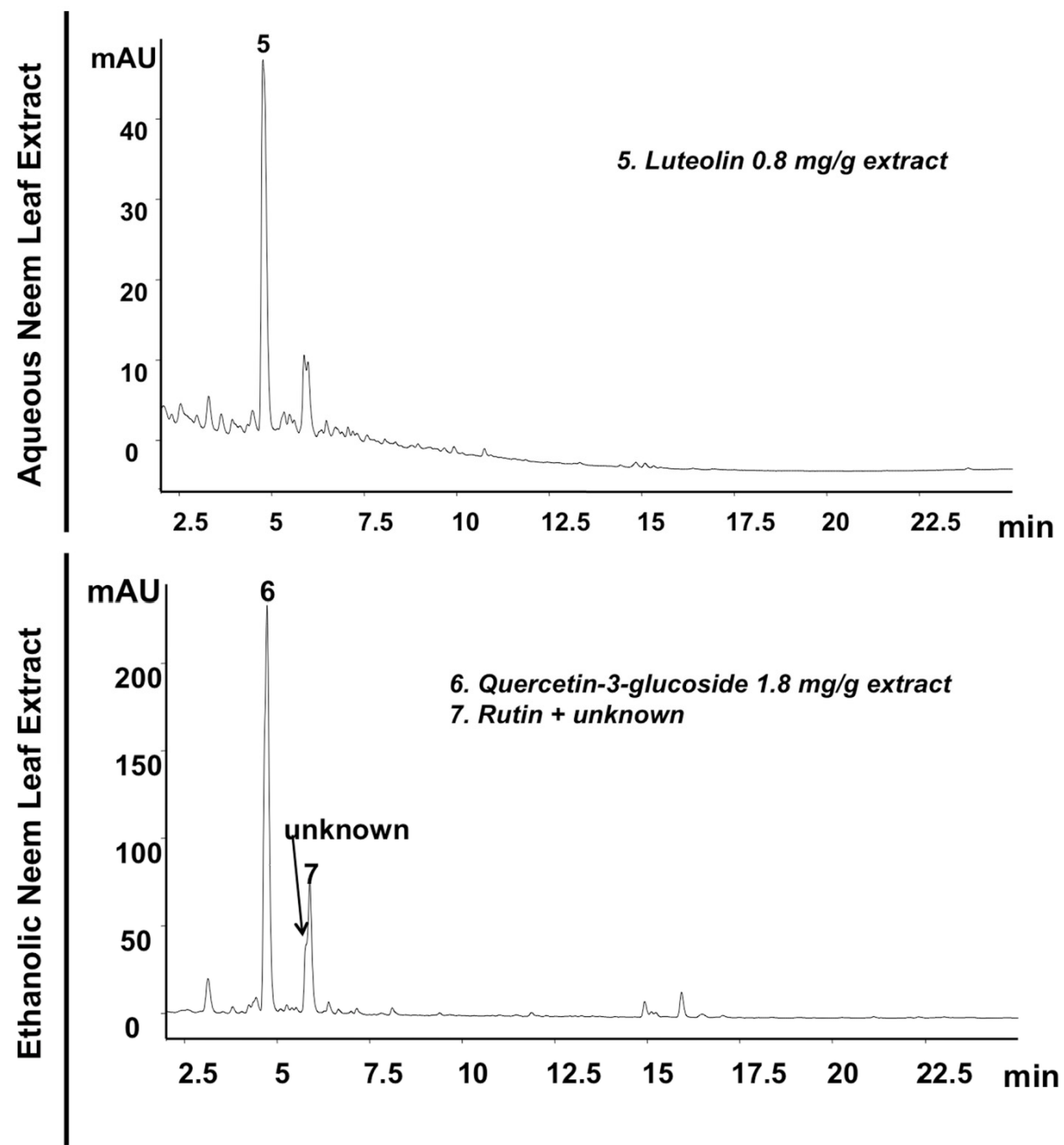

Figure 8. HPLC profile of aqueous and ethanolic Neem leaf extract. Neem extracts (aqueous and ethanolic extracts) were redissolved in 40:40:20 methanol:acetonitrile:water at $10 \mathrm{mg} / \mathrm{mL}$, followed by vortex and sonication for $5 \mathrm{~min}$ and filtration through 0.2 micron syringe filters. Diode array detection of the extracts and standard compounds were within the range of 210-380 nm. Identification of compounds was based on metabolomics library matching and quantification was based on cochromatography with authentic compounds. 

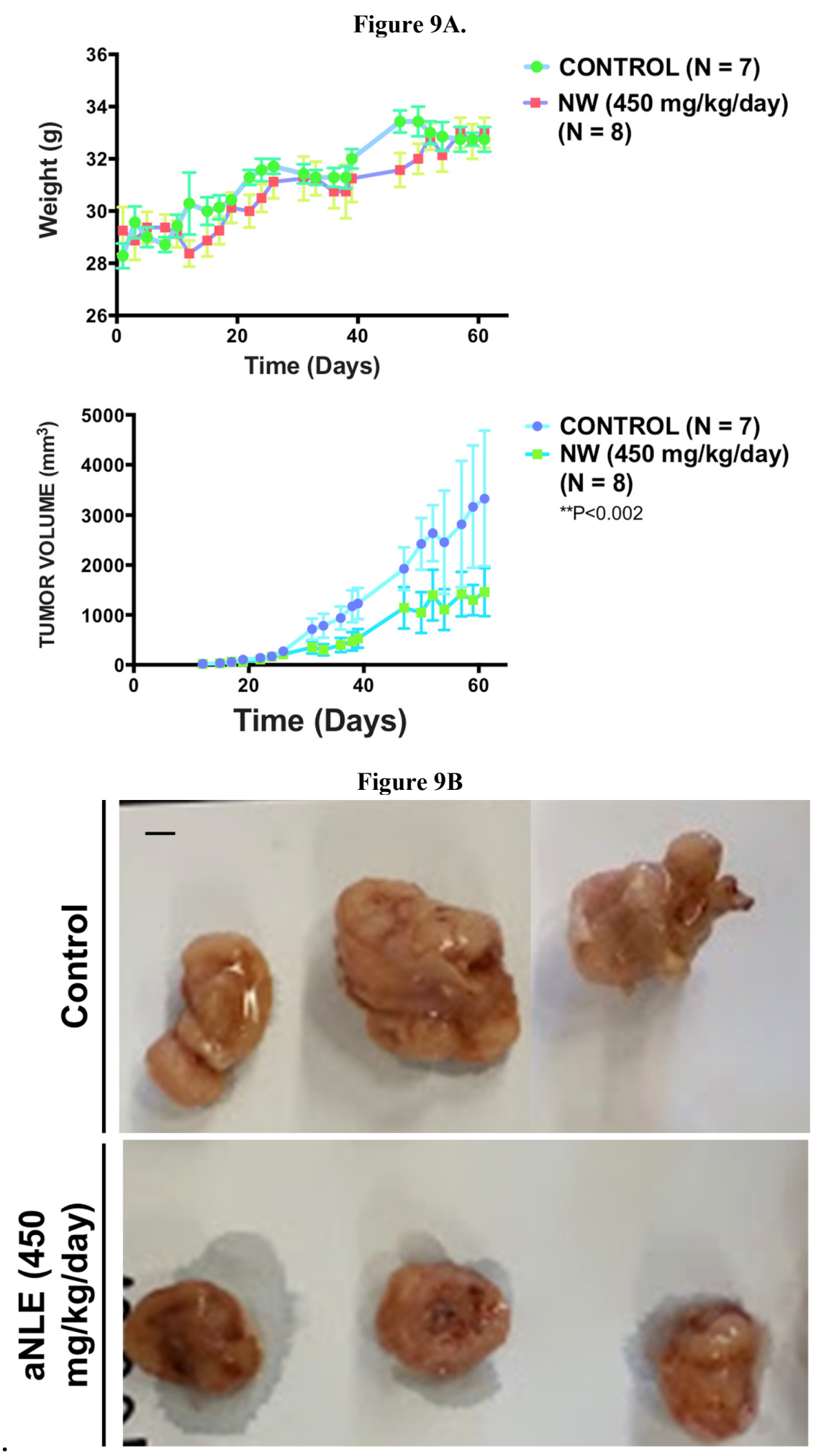

Figure 9. Aqueous Neem leaf extract is well tolerated and effective in mice. CD-1 nu/nu mice were subcutaneously injected with HT-29 cells on their left flank and tumours were developed mice were received aqueous NLE at a dose of 450 $\mathrm{mg} / \mathrm{kg} /$ day through their drinking water. Body weights and tumour volumes (A) of the mice were monitored throughout the study. Values are expressed as a mean \pm SEM. ${ }^{*} p<0.05$. (B) Images of tumors excised from the animals following the sacrifice of the animals. Scale bar $=25 \mu \mathrm{m}$ 


\section{DISCUSSION}

In this paper, we present our interesting findings that the aqueous and ethanolic extracts of Neem leaf displayed selective toxicity to human cancer cells. Furthermore, this multi-chemical extracts induced apoptosis by imposing oxidative stress and targeting mitochondria. Interestingly, oral delivery of the aqueous extract inhibited growth of human tumour xenografts in mice. For centuries, Neem (Azadarichta indica) has been used as an antibacterial (13), anti-malarial (14) and anti-diabetic (15). More than 135 compounds have been isolated from different parts of the Neem tree of which the majority fall under the category of isoprenoids (16). Among these compounds, nimbolide and azadarachtin have been found to possess anti-cancer properties amid many others (17). Although the bioactivity of some Neem components has been studied, the effect of crude extracts containing multiple bioactive compounds has not been investigated in detail. The cytotoxicity of crude Neem leaf extracts has been shown in some human cancers, however, their effect on non-cancerous cells has not been studied $(10,18,19)$. In this study, we used acute T-cell leukemia (E6-1) and colon cancer adenocarcinoma (HT-29) cells and their noncancerous counterparts, including human peripheral blood mononuclear cells to demonstrate cancer selective induction of apoptosis by NLE. In particular, it was found that NLEs were able to induce apoptosis in human cancerous cells without having the same effect on normal cells.

Apoptosis can occur intrinsically or extrinsically both of which converge on the mitochondria that plays a key role in apoptosis. The intrinsic pathway depends on mitochondrial membrane permeabilization initiated by pro-apoptotic proteins like Bax, in response to toxins, oxidative stress or chemotherapeutic agents, that leads to the release of pro-apoptotic proteins, including cytochrome $\mathrm{C}$, AIF and SMAC/DIABLO. These pro-apoptotic factors then promote downstream pathways leading to the progression of the apoptotic cascade (20). The extrinsic pathway does not depend on mitochondria directly, however, activated caspase 8 (after activation of death inducing signalling cascade (DISC)) cleaves a pro-apoptotic protein Bid, that leads to the activation of Bax and the permeabilization of the mitochondria (21).
Uncontrolled oxidative stress promotes destabilization of the mitochondria, leading to apoptosis (22). Interestingly, cancer cells already exhibit increased levels of cellular ROS due to a dependence on aerobic glycolysis for energy production (Warburg effect) as well as from oncogenic stimulation rendering them dependent on anti-oxidative mechanisms (23). Some studies have explored the possibility of exploiting this vulnerability to selectively induce cytotoxicity in cancerous cells (24). In the current paper, we have investigated the role of the oxidative stress and the mitochondria in NLE-induced apoptosis. It was found that ethanolic or aqueous NLE caused oxidative stress in E6-1 leukemia cells after treatment for 48 hours as displayed by an increase in whole cell ROS (Figure 5). Furthermore, isolated mitochondria treated with ethanolic NLE also exhibited increased ROS production, further suggesting the role of NLE in inducing oxidative stress in cancer cells (Figure 6). Furthermore, we observed collapse of mitochondrial membrane potential in cancer cells treated with NLEs (Figure 4). These observations indicate that multiple phytochemicals in NLE could trigger ROS production selectively in cancer cells by targeting mitochondria and/or other metabolic targets. Increased ROS production invariably leads to increased anti-oxidative defence response including increased expression of the Anti-oxidative response enzymes SOD and Catalase as seen in leukemia cells treated with ethanolic NLE. The aqueous extract did not change the expression levels of SOD and Catalase significantly, however, the ethanolic extract increased expression of both SOD and Catalase, with the highest expression at the latest time-point of 48 hours (Figure 7A-B). This increase in the oxidative stress response proteins correlated with the increase in ROS production by NLEs (Figure 5 and 6). It should be clear that although there is an increase in the expression of these proteins, this response was unable to combat oxidative stress-induced apoptosis imposed by NLE.

In contrast to single compounds, crude extracts derived from natural health products often contain many bioactive components that might have different targets. In developing therapies, a multitarget approach is often ideal as synergy between the components can lead to enhanced effects albeit at lower doses, preventing the toxicity one would 
obtain from a higher dose of a single compound. Furthermore, since it is well known that cancer cells often become resistant to targeted chemotherapies, a multi-targeted therapy is more beneficial as it could prevent the development of chemoresistance. In this study, we identified some of the known components that are present within the aqueous and ethanol NLEs. These include, Quercetin and Rutin (in the ethanolic extract) and Luteolin (in the aqueous extract) (Figure 8). These compounds have been studied for their activity as pure compounds, however in the context of multi-complexity with other compounds, in a natural extract, their activities are largely unknown. Moreover, in the context of cancer, there is much left to be done. The findings from this study indicate that these compounds play a large role in the oxidative stress response exhibited by these cancer cells, following treatment with NLEs and furthermore, the presence of these compounds, differently in the different extracts, confirm why there is a differential response in oxidative stress to NLE treatment (Figures 4-7).

Aqueous or alcoholic extracts prepared from traditional natural materials, without any chemical interference are generally safe and well tolerated. These multi-component extracts are also beneficial because they can be administered orally and safely to patients while maintaining activity. Neem leaf extracts have been used for thousands of years in several traditions indicating that they are well tolerated and safe. Indeed, we did not observe any significant difference in weight gain of the NLE fed mice versus the untreated control over a period 47 days indicating, that NLE was well tolerated (Figure 9A). More importantly, the oral delivery of NLE in drinking water was able inhibit the growth of human colon cancer xenograft tumours in these mice (Figure (9A and B). These findings provide the important validation of NLEs' anticancer potential as a safe, treatment for cancer.

These findings are extremely promising and warrant further study on the different components of NLE and their possible synergistic effects and mechanism of action. The targets related to metabolic vulnerabilities of cancer cells need to be identified and characterized in detail. The observations presented in this manuscript open up a new window of opportunity to develop natural health products (complex polychemical mixtures) as safe and potent anti-cancer therapies.

\section{ACKNOWLEDGEMENTS}

We gratefully acknowledge funding of this project by the Jesse \& Julie Rasch Foundation of Toronto, and donations from the Couvillon family of Windsor, Knights of Columbus Chapter 9671 and Pajama Angels of Windsor.

\section{REFERENCES}

1. Ferlay J, Soerjomataram I, Ervik M, Dikshit R, Eser S, Mathers C, Rebelo M, Parkin DM, Forman D, Bray F. No Title [Internet]. Cancer Incidence and Mortality Worldwide. 2012 [cited 2015 Jun 24]. Available from: http://globocan.iarc.fr

2. Hanahan D, Weinberg RA. The hallmarks of cancer. cell. Elsevier; 2000;100(1):57-70.

3. Ouyang L, Shi Z, Zhao S, Wang F, Zhou T, Liu B, et al. Programmed cell death pathways in cancer: a review of apoptosis, autophagy and programmed necrosis. Cell proliferation. Wiley Online Library; 2012;45(6):487-98.

4. Cunha KS, Reguly ML, Graf U, de Andrade HHR. Taxanes: the genetic toxicity of paclitaxel and docetaxel in somatic cells of Drosophila melanogaster. Mutagenesis. Oxford Univ Press; 2001;16(1):79-84.

5. Bauer A, Brönstrup $M$. Industrial natural product chemistry for drug discovery and development. Natural product reports. Royal Society of Chemistry; 2014;31(1):35-60.

6. Newman DJ, Cragg GM. Natural products as sources of new drugs over the 30 years from 1981 to 2010. Journal of natural products. ACS Publications; 2012;75(3):311-35.

7. Pratheeshkumar P, Sreekala C, Zhang Z, Budhraja A, Ding S, Son Y, et al. Cancer prevention with promising natural products: mechanisms of action and molecular targets. Anti-cancer agents in medicinal chemistry [Internet]. 2012;12(10):115984. Available from: http://www.ncbi.nlm.nih.gov/pubmed/22583402

8. Chaube, Shail K et al. "Neem (Azadirachta Indica L.) Leaf Extract Deteriorates Oocyte Quality by Inducing ROS-Mediated Apoptosis in Mammals."SpringerPlus 3 (2014): 464. PMC. Web. 13 Oct. 2015.

9. Nagini S, Priyadarsini RV. Azadirachta indica (Neem) and Neem Limonoids as Anticancer Agents: Molecular Mechanisms and Targets. Perspectives in Cancer Prevention-Translational Cancer Research. Springer; 2014. p. 45-60.

10. Chitta KS, Khan a NH, Ersing N, Swaika A, Masood A, Paulus A, et al. Neem leaf extract induces cell 
death by apoptosis and autophagy in B-chronic lymphocytic leukemia cells. Leukemia \& lymphoma. 2013;1(Cll):23721511.

11. Babykutty S, PS P, RJ N, Kumar MA, Nair MS, Srinivas $\mathrm{P}$, et al. Nimbolide retards tumor cell migration, invasion, and angiogenesis by downregulating MMP-2/9 expression via inhibiting ERK1/2 and reducing DNA-binding activity of NF$\kappa \mathrm{B}$ in colon cancer cells. Molecular carcinogenesis. Wiley Online Library; 2012;51(6):475-90.

12. Goswami KK, Barik S, Sarkar M, Bhowmick A, Biswas J, Bose A, et al. Targeting STAT3 phosphorylation by neem leaf glycoprotein prevents immune evasion exerted by supraglottic laryngeal tumor induced M2 macrophages. Molecular immunology. Elsevier; 2014;59(2):119-27.

13. Rajasekaran C. Investigations on antibacterial activity of leaf extracts of Azadirachta indica A. Juss (Meliaceae): a traditional medicinal plant of India. Ethnobotanical Leaflets. 2008;2008(1):161.

14. Dhar R, Zhang K, Talwar GP, Garg S, Kumar N. Inhibition of the growth and development of asexual and sexual stages of drug-sensitive and resistant strains of the human malaria parasite Plasmodium falciparum by Neem (Azadirachta indica) fractions. Journal of ethnopharmacology. Elsevier; 1998;61(1):31-9.

15. Dixit VP, Sinha R, Tank R. Effect of neem seed oil on the blood glucose concentration of normal and alloxan diabetic rats. Journal of Ethnopharmacology. Elsevier; 1986;17(1):95-8.

16. Biswas K, Chattopadhyay I, Banerjee RK, Bandyopadhyay U. Biological activities and medicinal properties of neem (Azadirachta indica). Current Science. 2002. p. 1336-45.

17. Priyadarsini RV, Murugan RS, Sripriya $P$, Karunagaran D, Nagini S. The neem limonoids azadirachtin and nimbolide induce cell cycle arrest and mitochondria-mediated apoptosis in human cervical cancer (HeLa) cells. Free radical research. 2010;44(6):624-34.

18. Baral R, Chattopadhyay U. Neem (Azadirachta indica) leaf mediated immune activation causes prophylactic growth inhibition of murine Ehrlich carcinoma and B16 melanoma. International immunopharmacology. Elsevier; 2004;4(3):355-66.

19. Kumar S, Suresh PK, Vijayababu MR, Arunkumar A, Arunakaran J. Anticancer effects of ethanolic neem leaf extract on prostate cancer cell line (PC-3).
Journal of ethnopharmacology. Elsevier; 2006;105(1):246-50.

20. Wang C, Youle RJ. The role of mitochondria in apoptosis*. Annual review of genetics. Annual Reviews; 2009;43:95-118.

21. Ashkenazi A. Targeting the extrinsic apoptosis pathway in cancer. Cytokine \& growth factor reviews. Elsevier; 2008;19(3):325-31.

22. Circu ML, Aw TY. Reactive oxygen species, cellular redox systems, and apoptosis. Free Radical Biology and Medicine. Elsevier; 2010;48(6):749-62.

23. Pelicano H, Carney D, Huang P. ROS stress in cancer cells and therapeutic implications. Drug Resistance Updates. Elsevier; 2004;7(2):97-110.

24. Raj L, Ide T, Gurkar AU, Foley M, Schenone M, Li $\mathrm{X}$, et al. Selective killing of cancer cells by a small molecule targeting the stress response to ROS. Nature. Nature Publishing Group; 2011;475(7355):231-4.

25. Nimmanapalli R, Bhalla K. Targets in Apoptosis Signaling. Methods in Molecular Biology. Springer; 2003. p. 465-83.

26. Simon H-U, Haj-Yehia A, Levi-Schaffer F. Role of reactive oxygen species (ROS) in apoptosis induction. Apoptosis. Springer; 2000;5(5):415-8.

27. Ryter SW, Kim HP, Hoetzel A, Park JW, Nakahira K, Wang X, et al. Mechanisms of cell death in oxidative stress. Antioxidants \& redox signaling. Mary Ann Liebert, Inc. 2 Madison Avenue Larchmont, NY 10538 USA; 2007;9(1):49-89.

28. Sheu S-S, Nauduri D, Anders MW. Targeting antioxidants to mitochondria: a new therapeutic direction. Biochimica et Biophysica Acta (BBA)Molecular Basis of Disease. Elsevier; 2006;1762(2):256-65.

29. Itahana Y, Han R, Barbier S, Lei Z, Rozen S, Itahana $\mathrm{K}$. The uric acid transporter SLC2A9 is a direct target gene of the tumor suppressor p53 contributing to antioxidant defense. Oncogene. Nature Publishing Group; 2014.

30. Saleem A, Harris CS, Asim M, Cuerrier A, Martineau L, Haddad PS, Arnason JT. A RP-HPLC-DADAPCI/MSD method for the characterisation of medicinal Ericaceae used by the Eeyou Istchee Cree First Nations. Phytochemical Analysis; 2010; 21(4): 328-339. 